\title{
AVALIAÇÃO DO GRAU DE DETERIORAÇÃO DE OBRA DE ARTE ESPECIAL LOCALIZADA NA ÁREA CENTRAL DE BRASÍLIA / DF - ESTUDO DE CASO
}

\author{
RAMOS, BRUNNA \\ Estudante \\ Centro Universitário do Distrito Federal - UDF \\ Distrito Federal; Brasil \\ brunnasramos@hotmail.com \\ PINHEIRO, JUÇARA \\ Estudante \\ Centro Universitário do Distrito Federal - UDF \\ Distrito Federal; Brasil \\ j.hingrid2@gmail.com
}

\author{
SILVA, KLEIÇA \\ Estudante \\ Centro Universitário do Distrito Federal - UDF \\ Distrito Federal; Brasil \\ klei.ca15@gmail.com \\ LIMA, NATANIEL \\ Professor \\ Centro Universitário do Distrito Federal - UDF \\ Distrito Federal; Brasil \\ nwontoon@gmail.com
}

\section{RESUMO}

As pontes e viadutos, denominadas Obras de Arte Especiais (OAEs), são de extrema importância para as grandes cidades pois tendem a proporcionar a locomoção de veículos de forma organizada e encurtar distâncias. Porém, segundo a norma ABNT NBR 6118 (2014), os tais geralmente são construídos em ambientes agressivos e, além disso, estão sujeitos a vários tipos de cargas decorrentes do tráfego de veículos, de variações de temperaturas etc., o que demanda uma manutenção adequada e periódica. Dentre os viadutos inspecionados pela Companhia Urbanizadora da Nova Capital do Brasil (NovaCap), empresa pública que gerencia e regulamenta o setor de construções na capital do Brasil, identificou-se que o viaduto situado na via N2, Esplanada dos Ministérios, Brasília/DF, que liga a via L2 Norte à avenida do Eixo Monumental, apresenta inúmeras manifestações patológicas tais como fissuras, eflorescências, corrosão de armaduras, carbonatação do concreto, etc. Diante disso, este trabalho tem como objetivo avaliar o grau de deterioração do viaduto supracitado, sem a utilização de ensaios laboratoriais, e apresentar métodos que possam ser utilizados para sua recuperação. Para avaliar o grau de deterioração da OAE, neste estudo de caso, utilizou-se o método apresentado na norma ABNT NBR 9452/2019, o do Departamento de Estradas e Rodagem (DER) e o GDE/UnB (2015), os quais indicaram a necessidade de manutenção no viaduto. Recomenda-se um ensaio de prova de carga na OAE para melhor comparar e discutir os resultados obtidos. Para a solução do problema, foi proposta a implantação de pingadeiras e buzinotes no tabuleiro e impermeabilização dos pilares e laje com a finalidade de impedir a reincidência das manifestações patológicas.

Palavras-chave: manifestações patologicas, grau de deterioração, inspeção de OAE, manutenção.

\begin{abstract}
Bridges and viaducts, named special engineering structures (SES), are extremely important for large cities, as they tend to provide organized vehicle locomotion and shorten distances. However, according to the ABNT NBR 6118 (2014), these structures are generally built in aggressive environments and are subject to various types of loads resulting from vehicle traffic, temperature variations and so on, what requires proper and periodic maintenance. Among the viaducts inspected by the Companhia Urbanizadora da Nova Capital do Brasil (NovaCap), a public company that manages and regulates the construction sector in the Brazilian capital, it was found that the viaduct located on the N2 route, Ministries Esplanade, Brasilia/DF, which connects the L2 North route to the Monumental Axis avenue, presents numerous pathological manifestations such as cracks, efflorescence, reinforcement corrosion, concrete carbonation and so on. Hence, this paper aims to evaluate the deterioration degree of the aforementioned viaduct and present methods rehabilitation methods for it. To assess the deterioration degree of the SES, in this case study, they were used the inspection methods presented by the ABNT NBR 9452/2019, the Department of Roads and Highways (DRH) and the GDE/UnB (2015). All methods showed a need for maintenance on the viaduct. A load testing on the SES is recommended to better discuss and compare the results. The installation of drainage elements on the deck and waterproofing the columns and slab of the viaduct are indicated as a solution to prevent the recurrence of pathological manifestations.
\end{abstract}

Keywords: pathological manifestations, deterioration degree, inspection of SES, maintenance. 


\section{INTRODUÇÃO}

Os viadutos e as pontes, denominadas Obras de Arte Especiais (OAEs), são de extrema importância para as grandes cidades, pois promovem a locomoção de veículos e encurtam distâncias de forma organizada. Porém, segundo a norma ABNT NBR 6118 (2014), essas OAEs geralmente são construídas em ambientes agressivos e, além disso, estão sujeitas a vários tipos de cargas decorrentes do tráfego de veículos, da ação do vento, de variações de temperaturas etc., que demandam uma manutenção adequada e periódica. A negligência quanto a este requisito tende a ocasionar o surgimento de manifestações patológicas que podem comprometer a funcionalidade e até mesmo reduzir a vida útil da OAE. Considerando esses fatos, é imprescindível a elaboração de um plano de inspeção da estrutura, de modo que nenhum dos estados limites sejam atingidos e a sua funcionalidade possa ser assegurada.

As OAEs estão sujeitas a vários tipos de manifestações patológicas as quais podem ser associadas a falhas na concepção ou execução do projeto (LIMA e PACHA, 2000; FIESS et al, 2004), qualidade/utilização inadequada dos materiais de construção, idade da estrutura e principalmente ausência de manutenções. De acordo com Helene (2003), no Brasil, as falhas de projeto representam cerca de $40 \%$ na origem das manifestações patológicas, sendo seguidas por erros no processo executivo, 28\%, problemas envolvendo insumos de construção, 18\%, utilização das instalações, 10\%, e planejamento da obra, 4\%. Cánovas (1988) ratifica que a ausência de um projeto de boa qualidade implica em modificações na obra, o que favorece erros de execução, ou seja, manifestações patológicas na execução podem ser consequência de um projeto mal elaborado.

Vale ressaltar que, em geral, os problemas patológicos são evolutivos e tendem a se agravar com o passar do tempo, além de acarretarem outros problemas associados ao inicial. Em outras palavras, as correções tendem a ser mais duráveis, mais efetivas, mais fáceis de executar e apresentam menores custos quanto mais cedo forem executadas, uma vez que os gastos com intervenções apresentam um crescimento exponencial em função do tempo (HELENE, 2003). Assim, as inspeções se tornam indispensáveis nas edificações, pois tem o objetivo de identificar as possíveis anomalias, o real desempenho da estrutura, além de prevenir acidentes e proporcionar manutenções menos onerosas.

Neste contexto, dentre os viadutos inspecionados pela Companhia Urbanizadora da Nova Capital do Brasil (NovaCap), empresa pública que gerencia coordena construções na capital do Brasil, identificou-se que o viaduto situado na via N2, Esplanada dos Ministérios, Brasília/DF (ver Figura 1), apresenta inúmeras manifestações patológicas tais como: fissuras, eflorescências, lixiviações, armaduras expostas com perca de seção transversal, carbonatação etc. Esta estrutura é composta por 4 pilares parede, dos quais dois encontram-se mais degradados, situação que demanda propostas de recuperação diferentes e compatíveis com os danos identificados em cada grupo. Nos pilares mais afetados pelos problemas patológicos, o trabalho de recuperação tende a ser mais complexo, envolvendo, geralmente, aumento da área de aço, perdida pelo processo de corrosão, e concretagem com concreto especial.

Diante disso, este trabalho tem como objetivo avaliar o grau de deterioração do viaduto supracitado, sem o uso de ensaios laboratoriais, e apresentar métodos que possam ser utilizados para a sua recuperação. As técnicas de recuperação propostas visam ser economicamente e tecnicamente viável, especialmente no quesito de tempo de obstrução do tráfego, pois o viaduto se encontra em uma área com um elevado fluxo de veículos.

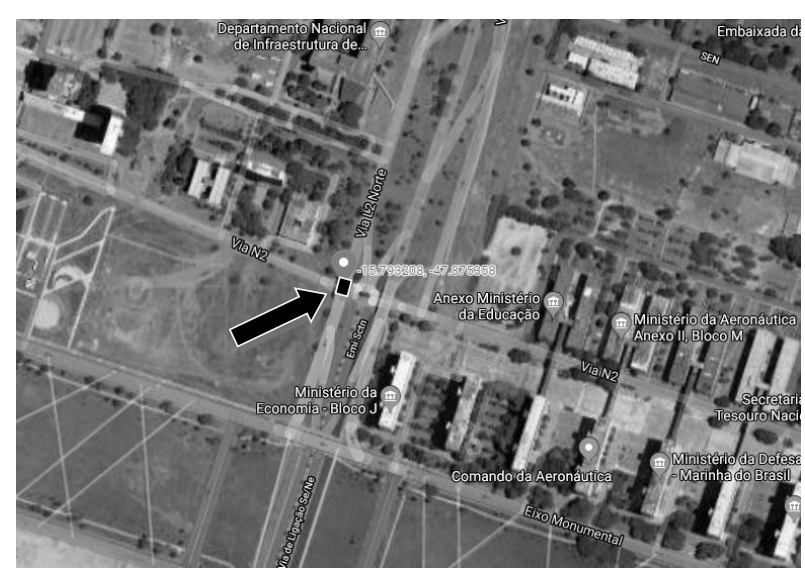

(a)

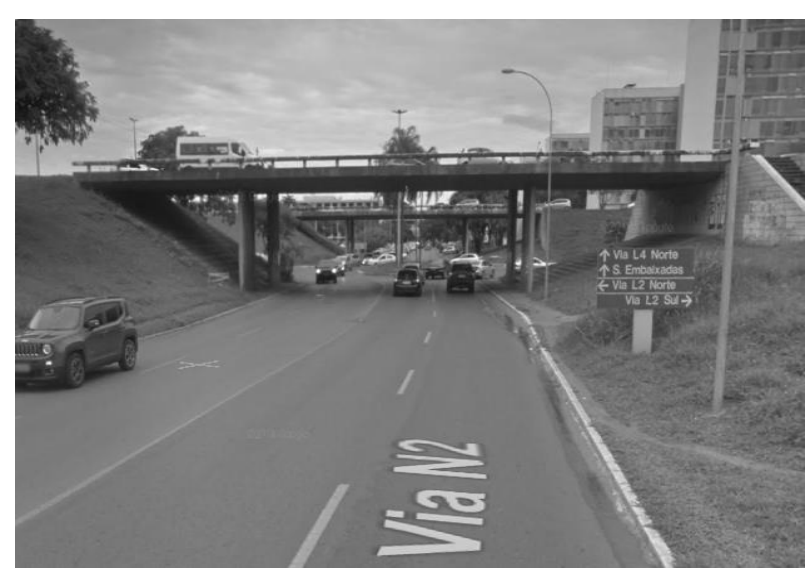

(b)

Figura 1 - Localização (a) e vista lateral do viaduto analisado (b). Fonte: Google Maps (2020) 
Para avaliar o grau de deterioração do viaduto, neste artigo serão utilizadas três metodologias: a primeira é a do GDE/UnB (2015), que tem como objetivo fazer um levantamento completo da estrutura, avaliando todas as possíveis anomalias e assim, designar formas para melhorar a vida útil da mesma - mais informações sobre o método podem ser encontradas no trabalho desenvolvido por Verly (2015) -; a segunda é a do Departamento de Estradas e Rodagem (DER) que visa melhorar e facilitar vistorias nas OAEs; sendo a terceira a metodologia apresentada na norma ABNT NBR 9452/2019: Inspeção de pontes, viadutos e passarelas de concreto - Procedimento.

\section{METODOLOGIA DE INSPEÇÃO DA OAE}

Atualmente no Brasil, diversos métodos de inspeção para OAEs foram desenvolvidos além do apresentado na ABNT NBR 9452/2019. Para avaliar o grau de deterioração do viaduto, neste estudo de caso, utilizou-se o método apresentado na norma supracitada, o do DER e o GDE/UnB (2015). A metodologia do DER foi inicialmente empregada na inspeção cadastral realizada pela Companhia Urbanizadora da Nova Capital do Brasil (NovaCap) na OAE e objetivou o cadastramento para monitoramento. O relatório de inspeção gerado pela NovaCap foi o único documento encontrado a respeito do viaduto supracitado. Os outros métodos foram aplicados por uma equipe de pesquisadores, autores deste trabalho, em inspeções rotineiras com o objetivo de verificar a evolução das anomalias, possibilitando assim uma comparação entre os resultados das três metodologias de inspeção de OAEs.

\subsection{Metodologia do Departamento de Estradas de Rodagem (DER)}

A metodologia do Departamento de Estradas de Rodagem (DER) foi desenvolvida por uma comissão técnica composta por profissionais do setor da construção civil com o objetivo de padronizar e facilitar procedimentos de vistorias em OAEs. Neste sentido, elaborou-se uma ficha de inspeção cadastral, composta pelos principais elementos estruturais de uma estrutura - pilar, laje/tabuleiro, vigas, aparelhos de apoio e fundações - e elementos não estruturais tais como guarda-corpo, barreira de proteção, iluminação, sinalização viária, vandalismo, tubulação, tráfego e estado de conservação da estrutura. Soma-se a isso a ficha de relatório fotográfico, com fotos de boa qualidade apresentando todos os ângulos da estrutura. Por fim, classifica-se a estrutura na sua superestrutura, mesoestrutura, infraestrutura e encontros com notas atribuídas que variam de 1 á 5 , onde 1 expressa o bom estado de conservação da obra e 5 expressa a urgência de manutenção da mesma.

Inicialmente, insere-se na ficha a identificação da OAE e classifica-se o tipo de obra, podendo ser ponte ou viaduto. Analisa-se o tipo de material utilizado na obra, tal como madeira, estrutura mista ou de concreto, e registra-se a data, horário e tempo (sol, nublado ou chuva) no momento da inspeção. Acrescenta-se ainda à ficha de vistoria o nome dos responsáveis técnicos e o desenho do esquema estrutural.

O segundo item da ficha consiste nos dados de inspeção e inicia-se com as informações dos encontros/acessos. Primeiramente, define-se quais serão as referências dos encabeçamentos, no caso do viaduto em estudo, o escabeçamento 01 está relacionado ao sentido Esplanada dos Ministérios e o encabaçamento 02, sentido DNIT. Para cada encabeçamento, devem ser analisados dados referentes a prumo, alinhamento e drenagem (classificados entre bom ou ruim), recalque, erosão do talude, fissuras, falhas de concretagem, concreto desagregado, manchas de fuligem, lixiviação (machas e estalactites), machas de óxido corrosão, armadura exposta, armadura corroída e armadura com perda de seção, sendo marcados "sim" quando identificados e "não" para quando não identificados na OAE. O segundo ponto desse item consiste na análise das lajes/tabuleiro em relação ao tipo e estado do revestimento, tipo de juntas, se são abertar ou revertidas, elementos de drenagem, pelo seu estado e características, existência de irregularidades no pavimento e os demais quesitos mencionados para o encabeçamento. Concernente ao vigamento, acrescenta-se ainda a verificação de flechas em relação aos itens de análise supracitados para o tabuleiro. Os aparelhos de apoio são inspecionados em relação a posição, limpeza, estado geral, drenagem e danos (ruptura/fissura). Os pilares são vistoriados em relação aos mesmos pontos de análise listados para o tabuleiro, acrescendo-se a verificação do prumo, recalque e alinhamento. Quanto à inspeção da infraestrutura, segue-se o mesmo procedimento de vistoria descrito para os pilares, somando-se a verificação de fundações desenterradas e erosão no terreno.

O terceiro item da ficha está relacionado a observações gerais. Analisa-se o guarda-corpo e barreira de proteção para veículos (sua existência, material e estado de deterioração), assim como a existência, situação e degradação da iluminação e sinalização viária. Verifica-se sinais de vandalismo e se passam tubulações pelo viaduto. O tráfego é classificado de acordo com sua característica (urbano, intermunicipal, interestadual, misto, pedestre ou rural) e intensidade. O estado de conservação da obra é avaliado com base no crescimento de vegetação entre elementos estruturais, na limpeza e no aspecto geral. Por fim, atribui-se a nota de consevação da obra. 
Vale salientar que a metodologia desenvolvida pelo DER foi elaborada com base na ABNT NBR 9452/2019: Inspeção de pontes, viadutos e passarelas de concreto - Procedimento, tendo como finalidade exclusiva a realização de inspeções cadastrais, não sendo aplicada para inspeções rotineiras, especiais ou extraordinária. Mais detalhes sobre os tipos de inspeções podem ser encontrados na norma ABNT NBR 9452/2019.

\subsection{Metodologia da ABNT NBR 9452/2019}

Após a vistoria cadastral executada pela NovaCap, os autores realizaram uma vistoria rotineira no viaduto a qual é definida pela norma ABNT NBR 9452/2019, item 4.2, por: "inspeção de acompanhamento periódico, visual, com ou sem a utilização de equipamentos e/ou recursos para análise ou acesso, realizado em prazo não superior a um ano, na qual deve ser verificada a evolução de anomalias já observadas em inspeções anteriores, bem como novas ocorrências, reparos e/ou recuperações efetuadas no período".

A norma supracitada, em seu anexo B, disponibiliza o roteiro básico e ficha para inspeção rotineira na qual devem ser levantados e atualizados os dados sobre a OAE, sendo essa ficha dividida em três partes. Inicia-se o preenchimento da ficha indicando o ano da inspeção rotineira, o código da OAE, a jurisdição e data da inspeção. A primeira parte contém as informações gerais, tais como: identificação e localização, histórico das inspeções e descrição das intervenções executadas ou em andamento como, por exemplo, reparos, alargamentos e reforços. A segunda parte, é referente ao registro de manifestações patológicas em elementos estruturais como superestrutura, mesoestrutura, infraestrutura, aparelhos de apoio, juntas de dilação, encontros e outros elementos, elementos da pista ou funcionais como pavimento, acostamento e refúgio, drenagem, guarda corpos e barreiras rígidas/ defensas metálicas, outros elementos (taludes, iluminação, sinalização, gabaritos e proteção de pilares), informações complementares e recomendações de terapias. A última parte trata da classificação da OAE quanto à sua estrutura, durabilidade e funcionalidade com valores de 1 a 5 , onde 1 representa a condição crítica e 5 a excelente. Em seguida, determina-se a nota final que deve ser a menor entre as notas que foram atribuídas a cada um dos parâmetros analisados e será correspondente ao estado geral em que a estrutura se apresenta, descritos no item 3.6 deste documento. Ademais, inclui-se o relatório fotográfico com no mínimo 8 fotos. É recomendada também a criação e/ou atualização do quadro resumo de inspeção rotineira, disposto no anexo B tabela B.2 da norma ABNT NBR 9452/2019.

É valido ressaltar que nessa metodologia todas as informações são descritas pelo responsável técnico da inspeção, não havendo um padrão de análise em modelo de checklist como apresentado na metodologia do DER, onde marca-se a existência ou não de uma manifestação patológica, ou se um determinado parâmetro se classifica como bom ou ruim.

\subsection{Metodologia do Grau de Deterioração da Estrutura (GDE/UnB)}

A metodologia GDE/UnB (2015) foi desenvolvida pela Universidade de Brasília (UnB) para determinar o grau de deterioração de estruturas de concreto, sendo composta por ficha, roteiro de inspeção e relatório fotográfico. Seu objetivo consiste em analisar e avaliar elementos estruturais nos mais variados aspectos: segurança, funcionalidade e estética, através de inspeções realizadas por engenheiros e técnicos com experiência na área.

A ficha é composta por informações gerais sobre localidade, natureza de uso, área construída, nome, idade, sistema construtivo, número de pavimentos, classe de agressividade de acordo com a norma ABNT NBR 6118 (2014) e pelos seguintes parâmetros de inspeção: identificação dos elementos estruturais, tipos de danos em estruturas tais como carbonatação, cobrimento deficiente, contaminação por cloretos, corrosão de armaduras, desagregação, deslocamento por empuxo, desvios de geometria, eflorescência, esfoliação, falha de concretagem, fissuração inaceitável, flechas excessivas, impermeabilização deficiente, infiltração, infiltração na base, manchas, obstrução de juntas de dilatação, recalque, sinais de esmagamentos do concreto e vazamentos em reservatórios. Todos estes danos devem ser averiguados para os pilares, vigas, lajes, escadas/rampas, cortinas (muros de arrimo), reservatórios (superior e inferior), blocos de fundação, juntas de dilatação e elementos de composição arquitetônica.

Além da ficha, a metodologia do GDE/UnB (2015) abrange cálculos para estimar o estado de deterioração da estrutura, família de elementos e para cada elemento da família, adotando-se um fator de ponderação $\left(F_{p}\right)$ pré-fixado para cada dano patológico - o qual varia de 1 a 5 , onde 1 é a situação mais favorável e 5 a mais desfavorável - e um fator de intensidade do dano $\left(F_{i}\right)$ - o qual pode variar de 0 a 4 , onde 0 corresponde a nenhuma lesão/dano e 4 ao estado crítico. A partir dessas informações é possível calcular: o Grau de Dano $(D)$, dado por (1), o Grau de Deterioração do Elemento $\left(G_{d e}\right)$, conforme (2) , o Grau de Deterioração da Família do elemento $\left(G_{d f}\right)$, dado por (3), e o Grau de Deterioração da 
Estrutura $\left(G_{d}\right)$, de acordo com (4). O $G_{d e}$ e o $G_{d}$ podem ser classificados como: baixo, médio, alto, sofrível e crítico, como mostra a Tabela 1.

Neste trabalho, para a aplicação dessa metodologia, inicialmente fez-se uma tabela no software Excel dividindo-se os elementos estruturais e adotando os fatores de ponderação $\left(F_{p}\right)$ de cada tipo de dano relacionando ao tipo de elemento. Foram considerados como elemento estrutural: os pilares, a laje, a cortina e as juntas de dilatação. Após essa análise, foi realizada a classificação do fator de influência $\left(F_{i}\right)$ de cada manifestação patológica. Realizado esse processo, foi calculado o grau de dano $(D)$ de cada manifestação patológica e em seguida o grau de deterioração do elemento $\left(G_{d e}\right)$. Por conseguinte, obteve-se o grau de deterioração de cada família $\left(G_{d f}\right)$, sendo essa família definida como a união de mesmos elementos estruturais, ou seja, família dos pilares, das lajes e das juntas de dilatação. É válido ressaltar que, para esse cálculo, somente foram considerados valores de $G_{d e}$ iguais ou maiores a 15 , como recomenda o método. Por fim, calculou-se o grau de deterioração da estrutura $\left(G_{d}\right)$.

$$
\left.\begin{array}{c}
D=0,8 F_{i} F_{p} \quad \operatorname{para} F_{i} \leq 2,0 \\
D=\left(12 F_{i}-28\right) F_{p} \quad \operatorname{para} F_{i}>2,0 \\
G_{d e}=D_{\max }\left[1+\frac{\left(\sum_{i=1}^{n} D_{i}\right)-D_{\max }}{\sum_{i=1}^{n} D_{i}}\right] \\
G_{d f}=G_{d e, \max }\left[1+\frac{\left(\sum_{i=1}^{m} G_{d e, i}\right)-G_{d e, \max }}{\sum_{i=1}^{m} G_{d e, i}}\right.
\end{array}\right]
$$

Tabela 1 - Classificação dos níveis de deterioração

\begin{tabular}{c|c|l}
\hline Nível de deterioração & Gd/Gde & \multicolumn{1}{c}{ Ações recomendadas } \\
\hline Baixo & $0-15$ & Estado aceitável. Manutenção preventiva. \\
\hline Médio & $15-50$ & $\begin{array}{l}\text { Definir prazo e natureza de nova inspeção. Planejar intervenção em longo prazo } \\
\text { (máximo 2 anos). }\end{array}$ \\
\hline Alto & $50-80$ & $\begin{array}{l}\text { Definir prazo para inspeção especializada. Planejar intervenção em médio prazo } \\
\text { (máximo 1 ano). }\end{array}$ \\
\hline Sofrível & $80-100$ & $\begin{array}{l}\text { Definir prazo para inspeção especializada rigorosa. Planejar intervenção em curto } \\
\text { prazo (máximo 6 meses). }\end{array}$ \\
\hline Crítico & $>100$ & $\begin{array}{l}\text { Inspeção especializada imediata e medidas emergenciais (alívio de cargas, } \\
\text { escoramento, etc.). Planejar intervenção imediata. }\end{array}$ \\
\hline
\end{tabular}

\section{RESULTADOS E DISCUSSÃO}

\subsection{Manifestações patologicas nos pilares-parede}

Verificou-se através da inspeção no viaduto que as manifestações patológicas mais evidentes estavam situadas nos pilares e na laje de tabuleiro. As juntas de dilatação e cortinas de contenção estavam revestidas, dificultando a visualização/acesso e, consequentemente, a análise da funcionalidade desses componentes do sistema estrutural.

Foram identificadas manifestações patológicas de corrosão na parte inferior de todos os pilares. Entretanto, o processo de corrosão da armadura principal e estribos mostrou-se mais avançado nos pilares 1 e 2 (ver Figura 2 para identificação 
dos pilares). No pilar 1, observou-se por meio do ensaio com fenolftaleína que a região na qual ocorreu o desplacamento do concreto (Figura 3b) estava afetada pelo processo de carbonatação e, utilizando-se um pacômetro (Figura 3c), verificou-se que o cobrimento da estrutura era insuficiente. In loco, foi realizada também a medição do diâmetro das barras com um paquímetro e estimou-se uma perda de seção transversal de aproximadamente 30\%. Além disso, foi possível identificar a presença de eflorescência na parte superior do respectivo pilar.

O pilar 2 apresentou uma área exposta a corrosão superior aos demais pilares e, de maneira similar ao que foi verificado no pilar 1, essa região estava localizada em sua parte inferior (Figura 4b). Observou-se a presença de armaduras rompidas, aparentemente por atos de vandalismo, bem como o forte odor de urina na base do pilar, fato que pode ter contribuído para a intensificação do processo de deterioração da estrutura.

Identificou-se também a presença de eflorescência no centro do elemento estrutural, comprovando a presença de passagem de água (ver Figura 4c). Nesse pilar também foi realizado o ensaio de carbonatação com fenolftaleína e por meio deste verificou-se que a região com armadura exposta estava totalmente carbonatada. O ensaio de pacômetria mostrou que o cobrimento no pilar 2 era semelhante ao do pilar 1 e a medição do diamêtro das barras também mostrou perda de seção transversal de aproximadamente $30 \%$.

Através da inspeção realizada, a causa das manifestações patológicas na base dos pilares foi ligada ao cobrimento insuficiente, o qual facilita a despassivação da armadura pelo processo de carbonatação do concreto e a consequente instalação de uma célula de corrosão, o ataque químico resultante da ação da urina e a ausência de impermeabilização na ligação do pilar ao elemento de fundação, permitindo a ascenção da água por capilaridade. De acordo com a NBR 6118 (2014), o cobrimento nominal adequado para pilares em um ambiente com classe de agressividade ambiental moderada deve ser igual a $30 \mathrm{~mm}$, ou seja, um valor aproximadamente $40 \%$ maior em relação ao valor médio medido, cerca de $21 \mathrm{~mm}$.

No pilar 3, observou-se o desplacamento do concreto em uma pequena região na base do pilar e o consequente processo de corrosão das armaduras (vide Figura 5). Foi possível verificar também a presença de manchas de fuligem, indicando a queima de materiais próximo à superfície do elemento estrutural. O calor liberado durante a combustão tende a afetar o concreto tornando-o mais frágil e menos resistente, fator que pode ter ocasionado o desplacamento do concreto nessa região. Ademais, como nos demais pilares, verificou-se que o cobrimento nominal do elemento estrutural era insuficiente em relação aos requisitos da ABNT NBR 6118 (2014).

O pilar 4 apresentou um estado de deterioração por corrosão mais avançado que o pilar 3, entretanto em um nível inferior em relação aos pilares 1 e 2 (ver Figura 6). As armaduras corroídas apresentaram perda de seção transversal inferiores a 30\%, conforme medições realizadas com um paquímetro, e não havia presença de manchas ou manifestações patológicas associadas à umidade. Verificou-se, no entanto, manchas de fuligem de forma semelhante ao que foi observado no pilar 3, indicando a queima de materiais próximo ao elemento estrutual, fator que pode estar associado à origem das manifestações patológicas.

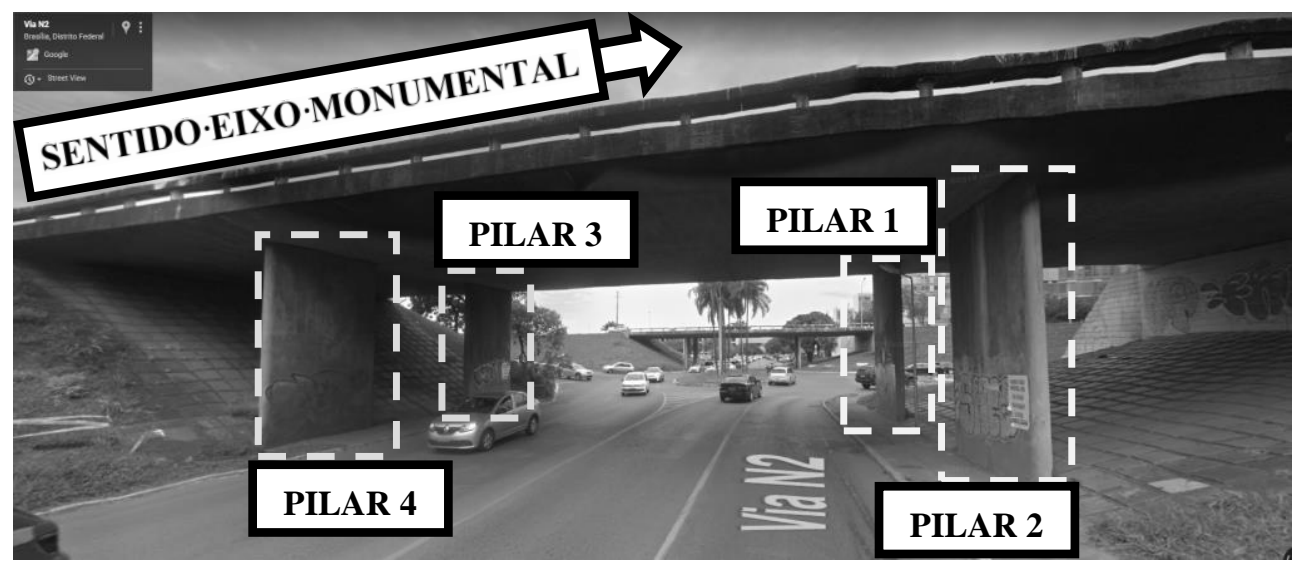

Figura 2 - Vista lateral do viaduto (Google Maps) (a) e identificação dos pilares (b). 


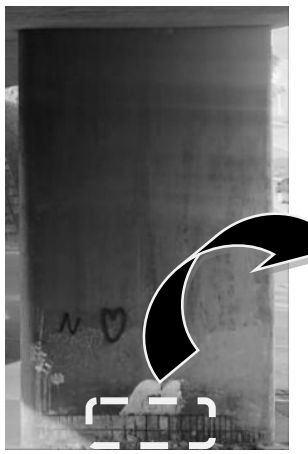

(a)

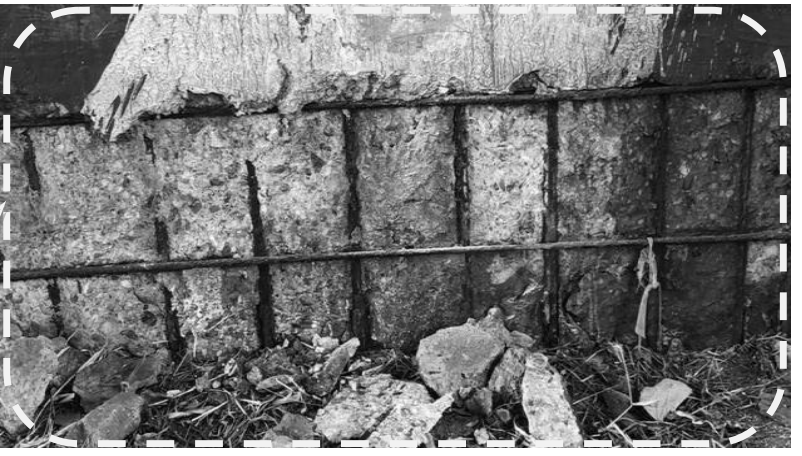

(b)

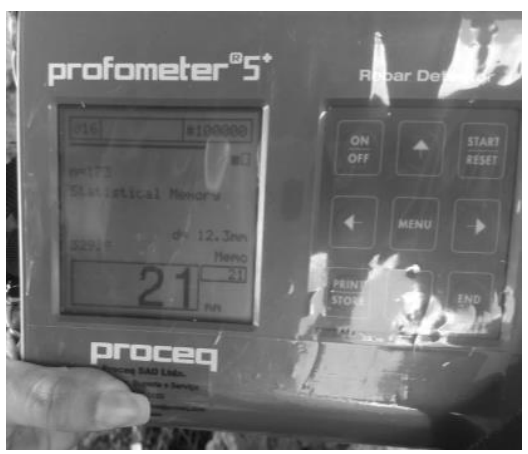

(c)

Figura 3 - Vista geral do pilar 1 (a); detalhe da zona afetada pelas manifestações patológicas (b); leitura do cobrimento com pacômetro.

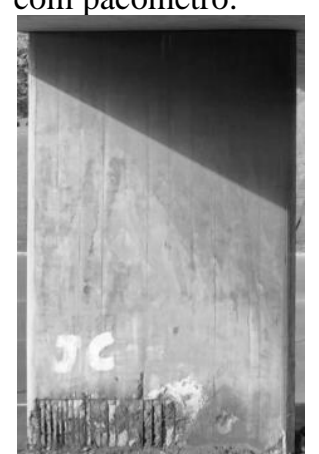

(a)

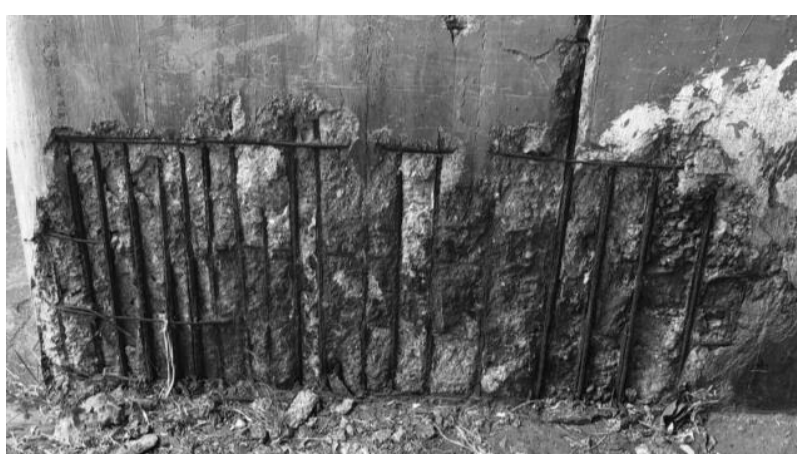

(b)

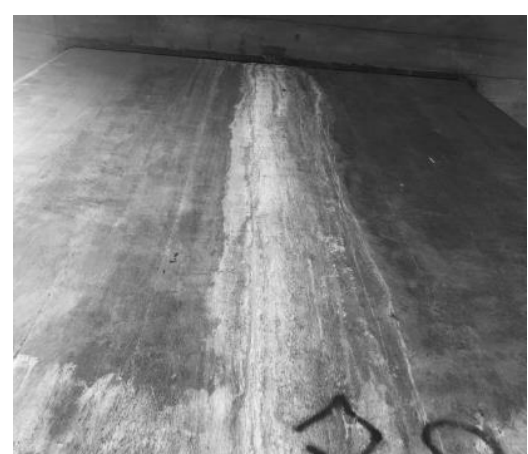

(c)

Figura 4 - Vista geral do pilar 2 (a); manifestações patológicas na base do pilar (b); eflorescência no centro do pilar (c).

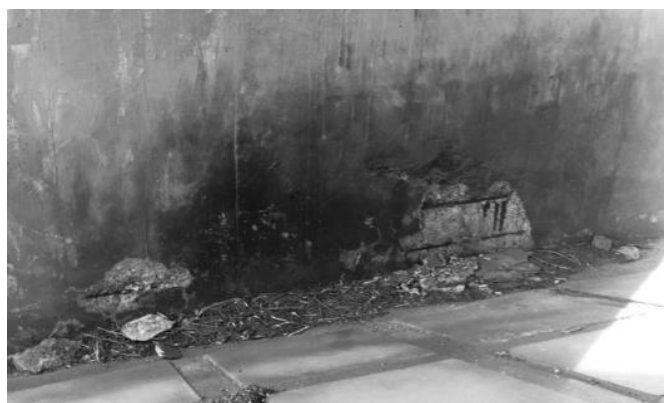

Figura 5 - Manifestações patológicas na base do pilar 3.

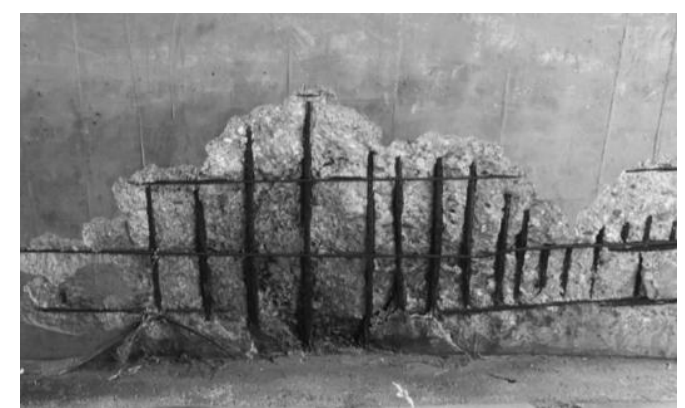

Figura 6 - Corrosão da armadura na base do pilar 4.

\subsection{Tabuleiro}

$\mathrm{Na}$ laje de tabuleiro do viaduto não foi identificada a utilização de um revestimento impermeabilizante nem a presença de elementos de drenagem tais como pingadeiras ou buzinotes. A ausência desses elementos, permitindo a percolação da água e a sua consequente infiltração na superfície do concreto, pode ser associada à origem de manifestações patológicas tais como manchas e eflorescência, as quais foram identificadas na parte lateral do tabuleiro (visualizar 
Figura 7a e 7b). Na sua parte inferior também foram encontradas pequenas fissuras e manchas de óxido de ferro, indicando a presença de uma célula de corrosão, conforme mostram as Figura 7c e 7d.

A ausência de reparo e a continuação das reações de oxidação das barras de aço ocasionam o aumento da seção transversal destas na região catódica da célula de corrosão, originando tensões de tração no interior do concreto, material que não resiste bem a esse tipo de esforço. Assim, este problema patológico tende a ocasionar o desplacamento do concreto, o que pode pôr em risco a segurança daqueles que trafegam por baixo do viaduto e fazer com que a estrutura atinja o estado limite de serviço (ELS) ou até mesmo o estado limite último (ELU). Vale ressaltar que não foi possível realizar nenhum ensaio no tabuleiro devido a sua altura elevada em relação ao nível da via e a ausência de equipamentos para vencer esse desnível.

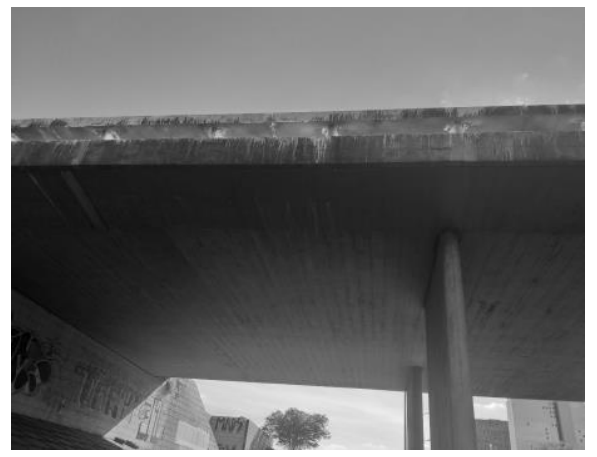

(a)

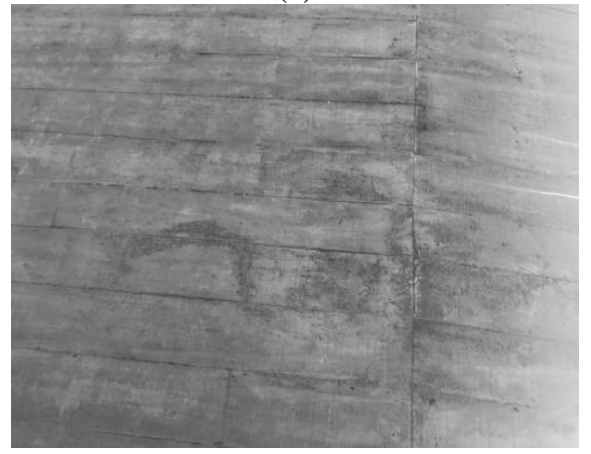

(c)

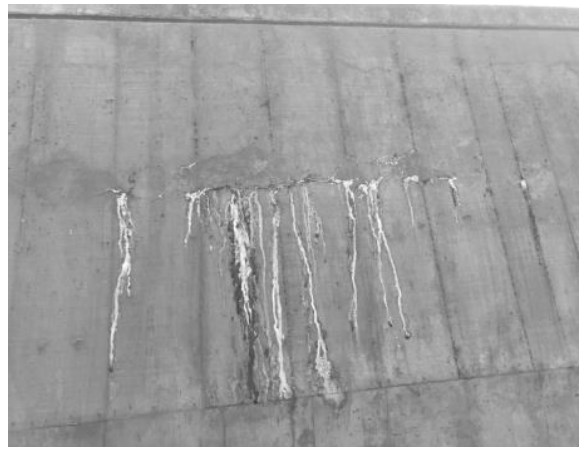

(b)

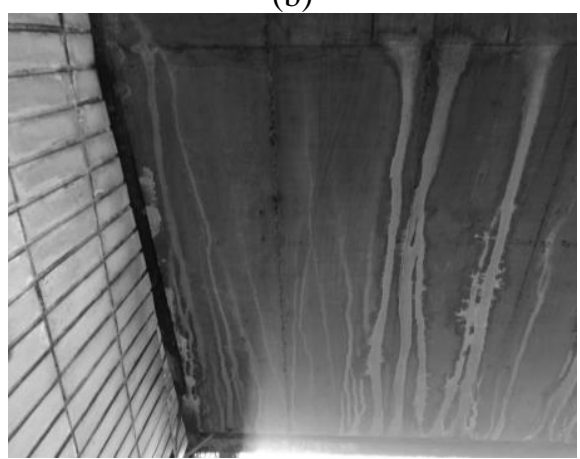

(d)

Figura 7 - Manifestações patológicas no tabuleiro: manchas, fissuras e eflorescência (a, b); manchas de corrosão e de infiltração $(c, d)$.

\subsection{Resultados pelo método DER}

Os índices que indicam o estado de conservação da estrutura apresentados na Tabela 2 foram determinados com base na experiência da equipe de inspeção da NovaCap. Como pode ser observado, dentre os componentes do viaduto analisados, segundo a metodologia do DER, apenas a mesoestrutura (pilares) demandou atenção quanto à serviços de reparos, sendo requisitada apenas a realização de manutenções pontuais no tabuleiro (superestrutura).

Vale ressaltar que este resultado se mostrou diferente em relação ao do método GDE/UnB (2015) e semelhante ao obtido através da ABNT NBR 9452/2019, o que já era esperado uma vez que a metodologia do DER tem como base essa norma.

Tabela 2 - Avaliação do nível de deterioração da OAE pela NovaCap

$$
\text { Nota de Conservação da Obra }
$$

1. Bom estado de conservação da obra

2. Necessita de manutenção pontual

3. Atenção - Manutenção

4. Necessita de fiscalização

5. Urgência de Manutenção
Superestrutura [2]

Mesoestrutura [3]

Infraestrutura [ ]

Encontros [2] 


\subsection{Resultados GDE/UnB}

De acordo com o método utilizado, o resultado obtido na família dos pilares foi o mais elevado devido a presença de corrosão, cobrimento deficiente, carbonatação, eflorescência e manchas. Esses itens apresentaram valores relevantes para o Fator de Influência $\left(F_{i}\right)$, descritos na tabela A1 do Manual de Aplicação da Metodologia GDE/UnB a OAEs proposto por Verly (2015), assim como quando associados ao Fator de Ponderação $\left(F_{p}\right)$, apresentado na tabela B1 do documento citado anteriormente, correspondem a um valor elevado de Dano $(D)$ e, consequentemente, a um Grau de Deterioração do Elemento $\left(G_{d e}\right)$ também. Os valores obtidos para os pilares 1, 2 e 4 implicam nível de deterioração crítico (ver Tabela 1), sendo sugerido pelo método a realização de inspeção especial emergencial e planejamento de intervenção imediata. O pilar número 3 apresentou o menor valor de Gde pelo fato de sua área corroída e os problemas patológicos relacionados a ele serem inferiores aos demais pilares. Por conseguinte, seu nível de deterioração foi dado como alto, sendo necessário de acordo com o método a definição do prazo para inspeção especializada e planejamento de intervenção em médio prazo, sendo considerado esse prazo de no máximo 1 ano.

A laje de tabuleiro apresentou resultados de $\mathrm{G}_{\mathrm{de}}$ entre 15 e 50 (ver Tabela 3), implicando no nível de deterioração médio de acordo com a Tabela 1. Essa classificação sugere a definição do prazo para nova inspeção e planejamento de intervenção em longo prazo, no máximo 2 anos. Esse valor encontrado se deu pela presença de apenas manchas e eflorescências no elemento estrutural, problemas que como já citados estão relacionados a ausência de drenagem na OAE. Os resultados obtidos pelo método GDE/UnB mais relevantes foram o da família dos pilares e da laje de tabuleiro. Os outros elementos analisados apresentaram resultados inferiores a 15 , onde nesse método não são relevantes. Os valores de $F_{r}$ atribuídos às famílias são apresentados devido a tabela de Fatores de relevância estrutural das famílias de elementos apresentada por Verly (2015), onde é atribuído o valor de $F_{r}$ igual a 5 para vigas e pilares principais e 4 para lajes, fundações, vigas secundárias e aparelhos de apoio. De acordo com a Tabela $1, G_{d}$ maior que 100 sujere-se a inspeção especialiazada imediata e medidas emergenciais na estrutura, como por exemplo: alívio de cargas, escoramento, dentre outros, assim como planejamento de intervençao imediada. No caso do viaduto analisado, tem-se $G_{d}$ igual a 158,5 (ver Tabela 3) onde se enquadra exatamente nessa classificação.

Tabela 3 - Grau de Deterioração da Estrutura $\left(G_{d}\right)$

\begin{tabular}{|c|c|c|c|c|c|}
\hline & & & & & \\
\hline Pilar 1 & Ude & $\sigma_{a j}$ & $t r$ & $\mathrm{~A}$ & $\underline{\sigma_{d}}$ \\
\hline & נינ, & \multirow{4}{*}{217,4} & \multirow{4}{*}{5} & \multirow{4}{*}{1086,9} & \multirow{5}{*}{158,5} \\
\hline Pilar 3 & 120,2 & & & & \\
\hline Pilar 4 & & & & & \\
\hline Mat 4 & 114,4 & & & & \\
\hline Tabuleiro & 18,4 & 18,4 & 4 & 73,6 & \\
\hline
\end{tabular}

\subsection{Resultados ABNT NBR 9452/2019}

Para analisar o grau de deterioração da estrutura conforme a ABNT NBR 9452/2019, foi utilizada a ficha de inspeção rotineira apresentada na tabela B.2 do anexo B desse código normativo, juntamente com os registros fotográficos e ensaios realizados, citados anteriormente no item 3.1.

De acordo com os resultados apresentados na Tabela 4, a superestrutura recebeu notas 3 e 4 que significam, respectivamente, regular e boa. Os índices atribuídos a estrutura e funcionalidade mostram a presença de pequenos danos que não comprometem a segurança estrutural e não causam desconforto ou insegurança ao usuário. $O$ índice atribuído à durabilidade indica a presença de pequenas e poucas anomalias que comprometem a vida útil da superestrutura em região de alta agressividade ambiental. Vale ressaltar que a referida norma utiliza apenas os termos alta e baixa agressividade ambiental, não indicando, no entanto, em quais situações esses termos se enquadram.

Tabela 4 - Ficha de classificação da OAE segundo a ABNT NBR 9452/2019

\begin{tabular}{|c|c|c|c|c|c|c|c|}
\hline \multirow{3}{*}{ Parâmetro } & \multicolumn{7}{|c|}{ Elemento } \\
\hline & \multirow{2}{*}{$\begin{array}{c}\text { Super } \\
\text { estrutura }\end{array}$} & \multirow{2}{*}{$\begin{array}{c}\text { Meso } \\
\text { estrutura }\end{array}$} & \multirow{2}{*}{$\begin{array}{c}\text { Infra } \\
\text { estrutura }\end{array}$} & \multicolumn{2}{|c|}{ Elementos complementares } & \multirow{2}{*}{ Pista } & \multirow{2}{*}{ Nota final } \\
\hline & & & & Estrutura & Encontro & & \\
\hline Estrutural & 4 & 3 & - & - & - & 4 & 3 \\
\hline Funcional & 4 & NA & NA & - & - & 4 & 4 \\
\hline Durabilidade & 3 & 2 & - & - & - & 4 & 2 \\
\hline
\end{tabular}


A mesoestrutura apresentou notas 2 e 3, sendo, respectivamente, ruim para a durabilidade e regular para o parâmetro estrutural. O parâmetro regular para estrutura foi escolhido por haver dano que pode gerar alguma deficiência estrutural, entretanto, sem sinais de comprometimento da estabilidade da OAE. A classificação ruim para a durabilidade, de acordo com a norma supracitada, é atribuída quando há anomalias médias ou grandes que comprometem a vida útil em agressividade ambiental alta. A infraestrutura e os elementos complementares (ver Tabela 4) não foram analisados pela ausência de acesso. A pista foi analisada e recebeu nota 4 para os três parâmetros, ou seja, foi classificada como boa.

De acordo com a Tabela 4 os menores valores para os parâmetros estrutural, funcional e durabilidade foram, respectivamente, iguais a 3, 4 e 2. Com isso, pode-se concluir que de acordo com a norma ABNT NBR 9452/2019, a parte estrutural da OAE precisa de acompanhamento dos problemas patológicos e sugere-se intervenções a médio prazo. Quanto à funcionalidade, o viaduto apresenta pequenos danos que não chegam a causar desconforto ou insegurança ao usuário. Por conseguinte, a durabilidade é apresentada como ruim, pois o viaduto apresenta anomalias que comprometem a sua vida útil. É válido ressaltar que, com exceção do parâmetro estrutural, a referida norma não apresenta um prazo de tempo para a realização de manutenções e inspeções posteriores.

\section{CONCLUSÃO}

Neste trabalho observou-se que as três metodologias de inspeção de Obras de Arte Especiais apresentaram classificações distintas quanto ao grau de deterioração da estrutura, sendo este resultado utilizado para o planejamento de novas inspeções ou intervenções no viaduto. Tais divergências podem estar relacionadas ao grau de subjetividade de alguns critérios de análise que dependem da experiência do profissional. O método do GDE/UnB (2015) foi o que apresentou o resultado mais crítico, demandando uma inspeção especial emergencial e planejamento de intervenção imediata. Nesta circunstância, conforme diretrizes do método, recomenda-se uma reavaliação na OAE estudada para verificar a presença de alguma inconformidade na atribuição de valores para os fatores de influência. De acordo com o método do DER, necessita-se de atenção especial para a manutenção da mesoestrutura e manutenção pontual dos encontos e tabuleiro. Por sua vez, o método da ABNT NBR 9452/2019 prevê uma inspeção especial e uma intervenção em médio prazo.

Assim, recomenda-se dar atenção aos problemas patológicos observados e realizar uma nova inspeção no viaduto analisado devido a sua importância para os usuários e pelo fato de que o preço dos reparos tende a se elevar de maneira exponencial com o tempo. Como proposta de intervenção, sugere-se a limpeza das áreas com processo de corrosão instalado, reforço dos pilares 1 e 2 com aumento de suas seções transversais utilizando-se concreto tradicional e adicionando-se um impermeabilizante em sua superfície, ou concreto autocicatrizante. Propõe-se também a realização de prova de carga no viaduto para certificação da necessidade de reforço estrutural devido à perda da área de aço e de concreto. No caso dos pilares 3 e 4, sugere-se a reparação da área de concreto desplacada com a utilização de argamassa impermeabilizante. Para impedir a reincidência das manifestações patológicas, sugere-se a implantação de pingadeiras e buzinotes no tabuleiro e impermeabilização na base dos pilares, a qual pode ser feita com argamassa impermeabilizante, resina epóxi, concreto autocicatrizante nos locais de reposição de área de concreto ou até mesmo com outro tipo de material que atenda a este propósito.

Por fim, considerando-se a segurança dos usuários e os custos crescentes das atividades de recuperação estrutural, conclui-se que é de extrema importância a realização de inspeções periódicas em pontes e viadutos associada ao cadastramento das OAEs pelo seu órgão responsável. 


\section{REFERÊNCIAS}

ASSOCIAÇÃO BRASILEIRA DE NORMAS TÉCNICAS. NBR 6118: Informação e documentação - Referências Elaboração. Rio de Janeiro, 2003

ASSOCIAÇÃO BRASILEIRA DE NORMAS TÉCNICAS. NBR 9452: Inspeção de pontes, viadutos e passarelas de concreto - Procedimento. Rio de Janeiro, 2019.

CÁNOVAS, M. F. Patologia e terapia do concreto armado. Tradução e adaptação de: Maria Celeste Marcondes $e t$ al., coordenação técnica L. A. Falcão Bauer. São Paulo: Editora PINI, 1988.

FIESS, J. R. F. et al. Causas da Ocorrência de Manifestações Patológicas em Conjuntos Habitacionais do Estado de São Paulo. In: CONFERÊNCIA LATINO-AMERICANA DE CONSTRUÇÃO SUSTENTÁVEL, ENCONTRO NACIONAL DE TECNOLOGIA DO AMBIENTE CONSTRUÍDO, 10., São Paulo, 2004.

HELENE, Paulo R. Do Lago. Manual de reparo, proteção e reforço de estruturas de concreto. São Paulo, Red Rehabilitar, 2003.

LIMA, J. M.; PACHA, J. R. S. Patologias das estruturas de concreto armado com ênfase à execução. Centro Tecnológico da Universidade Federal do Pará. Belém, 2000.

THOMAZ, E. Tecnologia, Gerenciamento e Qualidade na Construção. São Paulo: Pini, 2001.

VERLY, R. C. Avaliação de metodologias de inspeção como instrumento de priorização de intervenções em obras de arte especiais. Dissertação de Mestrado, Departamento de Engenharia Civil, Universidade de Brasília, Brasília, DF, 2015. $178 \mathrm{p}$. 